\title{
Facial Emotional Perception Training for Medical Students
}

\author{
Miriam Vázquez-Campo, Leticia Vidal, Angela Juana Torres, Raimundo Mateos, \\ Jose Manuel Olivares, Isabel García-Lado, Alejandro Alberto García-Caballero
}

School of Medicine, University of Santiago de Compostela, Santiago de Compostela, Spain

Email: alejandro.alberto.garcia.caballero@sergas.es

How to cite this paper: Vázquez-Campo, M., Vidal, L., Torres, A. J., Mateos, R., Olivares, J. M., García-Lado, I., \& García-Caballero, A. A. (2019). Facial Emotional Perception Training for Medical Students. Creative Education, 10, 1792-1801.

https://doi.org/10.4236/ce.2019.108128

Received: June 10, 2019

Accepted: August 4, 2019

Published: August 7, 2019

Copyright $\odot 2019$ by author(s) and Scientific Research Publishing Inc. This work is licensed under the Creative Commons Attribution International License (CC BY 4.0).

http://creativecommons.org/licenses/by/4.0/

(c) (i) Open Access

\begin{abstract}
Introduction: The aim of this study was to determine the applicability and efficacy of a tool for improving medical students' ability to recognize the facial expressions of emotions. Material and methods: We conducted a controlled intervention study with 98 medical students. The control group underwent a 45 -minute class whose content was not targeted at the rehabilitation objective, while the intervention group was trained to recognize emotions through tutorials and games on eye, face and microexpression recognition using https://www.e-motionaltraining.com/ program. All participants were assessed before and after the intervention with Ekman Faces Test. Results: When comparing the scores between the groups, we observed significant preintervention postintervention improvements in the intervention group in the emotions of anger $(p<0.001)$, sadness $(p=0.031)$ and fear $(p=$ $0.007)$. Moreover, when comparing the students who performed pretest at Q1 vs. Q4 there were significant differences in change scores in happiness and anger ( $p=0.005$ and $p=0.003$, respectively), with the students who achieved lower results in the initial assessment (Q1), thereby showing greater improvement. Conclusions: We can conclude that training medical students in recognizing facial emotions as part of their routine classroom training is feasible. The participants who most benefited were those who initially had lower scores in emotion recognition.
\end{abstract}

\section{Keywords}

Empathy, Medical Students, Nonverbal Communication

\section{Introduction}

Humans are social creatures and spend most of their lives interacting with each other. A fundamental skill for successfully conducting this interaction lies in 
"empathy", i.e., the ability to perceive, share, understand and participate in the feelings of others, both positive and negative (Lockwood, 2016).

One key characteristic of patient-centered care is the physician's ability to interpret and channel the emotions that arise within the therapeutic relationship. The physician must contain the patient's behavior and emotions appropriately. Unfortunately the dialectic response is not restricted to virtuous circles and physician's responses could incite negative reactions in users, which even can lead to demands or verbal or physical aggressions (Mead \& Bower, 2000; Little et al., 2001; Norfolk et al., 2007). The practitioner's skills in recognizing and managing their patients' emotional signals are associated with positive results in the quality of patient care (Zachariae et al., 2003; Squier, 1990; Kim et al., 2004; Hojat et al., 2011; Stewart et al., 2000). Over the last decade, attention has been focused on studying practitioner's responses to their patients' emotional concerns and signals; however, most of these studies have been limited to analyzing verbal communication (McCabe et al., 2002; van den Brink-Muinen \& Caris-Verhallen, 2003; Van Dulmen et al., 2003; Langewitz et al., 2003; Eide et al., 2003, Zimmermann et al., 2003; Van Dulmen \& van den Brink-Muinen, 2004; Rimondini et al., 2004).

Empathy in healthcare professions enjoys a certain prestige but has been rarely studied from the scientific point of view. In recent decades, however, the importance of empathy has been demonstrated in terms of improving therapeutic compliance (Becker \& Maiman, 1975), diagnostic reliability (Mercer \& Reynolds, 2002) and patient satisfaction (Kim et al., 2004), reducing the number of errors and demands (Tamblyn et al., 2007), improving health results (West et al., 2006), reducing burnout and improving the physician's wellbeing, with empathetic clinicians being perceived as more competent (Kraft-Todd et al., 2017).

The E-M-P-A-T-H-Y model has recently been proposed (E-eye contact, $\mathrm{M}-$ facial expression muscles, $\mathrm{P}$ - posture, $\mathrm{A}$-affection, $\mathrm{T}$-tone of voice, $\mathrm{H}$-actively hearing the patient, and $\mathrm{Y}$-your response) (Riess \& Kraft-Todd, 2014).

This abbreviation helps us remember the keys to nonverbal communication, both in situations of cultural diversity where verbal communication can be limited, in situations where the patient is reluctant to show disagreement and in those contexts in which detecting these subtle signals by the physician can be a starting point for discussion and shared decision making, which ensure better compliance and patient wellbeing.

Ekman's article "Emotions revealed: recognizing facial expressions" (26), states that recognizing patients' facial expressions, including those that are less obvious (microexpressions), can be of considerable usefulness for healthcare practitioners in their relationships with patients. Following this advice we devised this pilot study in order to determine the applicability and efficacy of a tool for improving medical students' ability to recognize facial emotions.

\section{Methods and Materials}

\subsection{Study Design}

Controlled intervention study. 


\subsection{Sample and Framework of Action}

Fourth-year medical students of the University of Santiago de Compostela (Galicia, Spain).

Based on previous studies by the same research group on populations with disease (27 - 28) and assuming a 95\% confidence level, the necessary sample size was 98 students.

In our school, each course is composed of 300 students, divided into 3 groups and each group is splitted for seminars in subgroups of 50 students ( $A$ and $B)$. Given the required sample size of nearly 100 students the group lead by Prof. Torres and Prof. García Caballero was selected for convenience. Subsequently an individual external to the study randomized the subgroups ( $A$ and $B$ ) to each condition (control group and intervention group).

\subsection{Intervention}

The intervention was performed in a normal classroom using the class projector and a computer connected to the Internet and running the e-Motional Training program (http://www.emotionaltraining.com). The training was guided by the professor (AGC) and lasted 45 minutes.

Each question was assessed by the group as a whole, and the students were requested to participate out loud in solving the games. In the event of a lack of consensus, a show of hands was employed to vote on the most appropriate option, which was then entered into the computer. The computer then provided feedback on this response.

The program's modules devised for facial emotion recognition that were used in this experiment were chosen because they were not time sensitive, i.e. the question was posed and it can be asked to the classroom allowing some debate to reach a consensus without being prompted by time constrictions. These modules were designed to improve the recognition of facial expressions of emotions in individuals with severe mental disorders, the selection and validation of the pictures as well as the usefulness of the program in patients with schizophrenia has been published elsewhere (Maroño Souto et al., 2018; Vázquez-Campo et al., 2016).

First, the participants were shown six video tutorials with detailed explanations of the characteristics of each basic emotion. Subsequently, they were shown four tutorials dedicated to explaining the differences between emotions that are typically confused. Afterwards, the participants were taken to the training on emotions portraited in the eyes' region. The game was composed of 15 essays depicting two photographs of the eyes randomly selected from a pool of 100 pictures were only one was the correct answer. After three games (45 photographs) a similar game with photographs of mouths was played and the process repeated. The participants then moved on to training with still frames of entire faces where they had to choose between seven options (six basic emotions and neutral faces). The program randomly selected the pictures from a pool of 300 photographs and each game was composed of a series of 15 pictures. As in the previous essays the game was played three times. Lastly, the participants moved 
on to a training section on recognizing microexpressions (expressions that last less than $250 \mathrm{~ms}$ ). The videos were randomly selected from a pool of 50. Each game was composed of 10 essays and the students performed three games (30 videos). When the students were not sure on the response they were shown the video as many times as required at normal speed (not in slow motion) in order to reach a consensus. If they failed the video was then showed in slow motion as with playing it with patients.

Control group. This group of participants underwent a 45-minute class whose content was not targeted to the rehabilitation of emotions.

\subsection{Assessment}

Ekman 60 Faces Test (Young et al., 2002). This test helps assess emotional perception and consists of 60 photographs that represent the six basic emotions (i.e., happiness, sadness, anger, fear, surprise and revulsion). An overall score of 60 indicates the best possible performance, and each basic emotion also has a maximum score of ten points. This test was presented on a computer using PowerPoint, while the participants were given a grid on a sheet of graph paper for their answers. This test was performed anonymously, and only the participants' age and sex were recorded. The initial assessment was conducted just before starting the training; the final assessment was conducted after the training.

\subsection{Statistical Analysis}

Initially, we performed a descriptive analysis in which the qualitative variables are expressed as frequency and percentage. The continuous variables are expressed as means \pm standard deviation and medians (range). To determine the normality of the variables, we performed the Kolmogorov-Smirnov test. We performed parametric and nonparametric tests (chi-squared, Mann-Whitney U and Wilcoxon) to determine the potential association between the study variables. We performed an ANCOVA analysis to determine the effect of the intervention, using the change scores (differences in each component of the final values-initial values). In all the analyses, we considered differences with $p<$ 0.05 as statistically significant. The analysis was conducted with SPSS 22.0 and Epidat 4.1.

\subsection{Ethical Issues}

In this case, authorization from the ethics committee was not required given that a clinical sample was not employed. The study complied with the fundamental principles established in the Declaration of Helsinki, in the Council of Europe Convention regarding Human Rights and Biomedicine, as well as the requirements established in Spanish law in the biomedical research setting, the protection of personal data and bioethics.

All participants included in this study were informed in writing of the study characteristics and voluntarily agreed to participate. 


\section{Results}

The recruited sample consisted of 98 fourth-year medical students from the University of Santiago de Compostela, Spain; 58 were assigned to the control group, and 40 were assigned to the intervention group.

In terms of the sample's characteristics, there was a predominance of women (63.3\% women vs. $36.7 \%$ men) and the median age was 21 years (range, $20-31$ years) (Table 1).

Before the intervention, the best recognized emotions were happiness and surprise; in contrast, the most poorly recognized were disgust, sadness and fear. When performing the same comparison by groups, we observed no differences between the two groups initially, except in the emotion of disgust in which the controls obtained better results $(p=0.002$; Mann-Whitney $\mathrm{U}$ test). After the intervention, we observed that the scores for the control group in the various emotions were maintained or worsened; this worsening was significant for the emotions of sadness and fear (Table 2).

In the intervention group, we observed improvement in the emotions of anger, sadness and fear (Table 2 and Table 3 ).

In order to control these intragroup changes that could be attributed to test-retest effect we performed an ANCOVA (Table 3) showing significant Change scores for disgust and anger.

To conclude the analysis, we performed a comparison between the $25 \%$ of those who achieved lower results in the pretest (Q1) with $25 \%$ of those who achieved better results (Q4). We observed significant differences in happiness and anger ( $p=0.005$ and $p=0.003$, respectively), with the students who achieved lower results in the initial assessment, thereby showing greater improvement (Table 4).

Table 1. Sample distribution.

\begin{tabular}{ccccc}
\hline & & Control Group & Intervention Group & $p$ \\
\hline Sex, n (\%) & Male & $21(36.2)$ & $15(37.5)$ & 0.896 \\
& Female & $37(63.8)$ & $25(62.5)$ & \\
Age, years (range) & & $21(20-31)$ & $21(20-28)$ & \\
\hline
\end{tabular}

Table 2. Ekman test results by group.

\begin{tabular}{ccccccc}
\hline Ekman & $\begin{array}{c}\text { Control Pre } \\
\text { Median (range) }\end{array}$ & $\begin{array}{c}\text { Control Post } \\
\text { Median (range) }\end{array}$ & $p \quad \begin{array}{c}\text { Interv.Pre } \\
\text { Median (range) }\end{array}$ & $\begin{array}{c}\text { Interv.Post } \\
\text { Median } \\
\text { (range) }\end{array}$ & $p$ \\
\hline Happiness & $10[8-10]$ & $10[9-10]$ & 0.157 & $10[8-10]$ & $10[9-10]$ & 0.317 \\
Disgust & $8[5-10]$ & $8[4-10]$ & 0.671 & $7[2-10]$ & $8[2-10]$ & 0.13 \\
Anger & $9[5-10]$ & $9[5-10]$ & 0.925 & $8[5-10]$ & $9[5-10]$ & $<0.001^{*}$ \\
Surprise & $10[8-10]$ & $10[6-10]$ & 0.794 & $10[7-10]$ & $10[4-10]$ & 0.700 \\
Sadness & $9[5-10]$ & $9[4-10]$ & $0.004^{*}$ & $8[4-10]$ & $9[6-10]$ & $0.031^{*}$ \\
Fear & $9[4-10]$ & $8[2-10]$ & $0.004^{*}$ & $8[5-10]$ & $10[5-10]$ & $0.007^{*}$ \\
\hline
\end{tabular}


Table 3. Change by emotion.

\begin{tabular}{cccccc}
\hline & \multicolumn{2}{c}{ CONTROL GROUP } & \multicolumn{3}{c}{ INTERVENTION GROUP } \\
\hline & Median & Range & Median & Range & $p$ \\
\hline Change Happiness & 0 & $-1-1$ & 0 & $-1-2$ & 0.840 \\
Change Disgust & 0 & $-3-3$ & 1 & $-3-5$ & $0.011^{*}$ \\
Change Anger & 0 & $-3-4$ & 1 & $-1-3$ & $0.001^{*}$ \\
Change Surprise & 0 & $-3-1$ & 0 & $-6-2$ & 0.442 \\
Change Sadness & 1 & $-2-3$ & 0 & $-2-3$ & 0.827 \\
Change Fear & 0.5 & $-2-3$ & 1 & $3-5$ & 0.552 \\
\hline
\end{tabular}

Table 4. Comparison P75 - P25.

\begin{tabular}{lcccc}
\hline & & Median & Range & $p$ \\
\hline \multirow{2}{*}{ Change Happiness } & Q1 & 0 & $-1-2$ & $0.005^{*}$ \\
& Q4 & 0 & $-1-1$ & \\
Change Disgust & Q1 & 1 & $-3-3$ & 0.219 \\
Change Anger & Q4 & 0 & $-3-5$ & \\
Change Surprise & Q1 & 2 & $-2-4$ & $0.003^{*}$ \\
Change Sadness & Q1 & 0 & $-3-3$ & \\
& Q4 & 0 & $-1-2$ & 0.084 \\
Change Fear & Q1 & 1 & $-6-2$ & \\
& Q4 & 1 & $-2-3$ & 0.062 \\
& Q1 & 1 & $-2-3$ & 0.389 \\
\hline
\end{tabular}

\section{Discussion and Conclusion}

Patient-centered care is becoming increasingly important in the healthcare setting to provide precise and culturally competent emotional care.

Physicians typically indicate that time constraints are the main obstacle in implementing patientcentered care and end up sidelining empathy in order to fulfill their tasks in the shortest time possible and to meet the healthcare objectives indicated for them by the system (Ekman, 2004).

This approach does not seem like the best option, given that empathy in medicine has been shown to be truly important in achieving not only patient satisfaction but also improved health results and treatment compliance, contributing to shared medical decision-making and decreasing complaints of negligence (Mercer \& Reynolds, 2002; Tamblyn et al., 2007; West et al., 2006; Kelley et al., 2014).

The educational model known by the abbreviation E-M-P-A-T-H-Y focuses on the nonverbal behavior of medical communication and has been shown to 
not require additional time for its implementation (Riess \& Kraft-Todd, 2014). This model provides a checklist on aspects to perceive in the patients' attitude and in the skills needed to respond to these emotional signals.

The letter $\mathrm{M}$ in the abbreviation refers to the muscles of facial expression. This is a key component of nonverbal communication, and studies indicate that the ability to empathize is related to the ability to decipher facial expressions (Riess \& Kraft-Todd, 2014).

Our study was aimed at improving facial emotion recognition as a necessary basic skill for improving the empathic abilities of medical students.

The findings suggest a clear practical implication of incorporating empathic nonverbal training in medical education (Haxby et al., 2002; Endres \& Laidlaw, 2009). Given the important consequences of these nonverbal elements in the success of health interventions, it is important that physicians learn this type of skill in a standardized manner over the course of their studies.

In our study, even though the reduced time intervention and ceiling effects, the intervention group improved their emotion recognition after training both in disgust and anger, emotions strongly related with confrontation and aversion, and belonging to a different cluster from submission signals provided by fear and sadness.

The results of our study indicate that the students who initially scored worse on the Ekman test improved the most after the training in happiness and anger, even though happiness reached not significant differences between groups, anger as we have seen is one of the emotions improved by the intervention. These results contrast with those found by other studies (Endres \& Laidlaw, 2009) that, after training students in microexpressions, found that those who initially demonstrated good overall clinical communication benefited from the training, while those who initially performed at a low level did not improve. In this study, however, the students were stratified according to their communication skills, which do not have to directly correlate with the ability to recognize the facial expressions of emotions. Further studies are needed to assess the relationship between these two variables.

The results we present are consistent with our previous experience in patients with schizophrenia (Mentes et al., 2004; Achinard, 2000) in which the groups with the lower pretest results were the ones that benefitted most from the intervention.

Our results have practical implications and arise some hypothesis that should be addressed in the future. If this preliminary results are correct improving anger and disgust recognition in real academic settings could be possible, probably even with self-training with an app. Anger and disgust are interesting goals because they are not related with compassion and empathy (generally associated with vocational sanitary personality features) but with rejection and conflict, distant playgrounds for medical students and unfortunately common in daily practice.

Our preliminary results prompt research in emotion recognition at grade level 
with the aim of facilitating patient-doctor relation and reducing demands and aggressive behaviours.

\section{Study Limitations}

The sample size calculation was extrapolated from other studies performed with patients. It would be advisable to reassess the sample size calculation based on the results of this study, because a larger size could perhaps obtain significant differences in other emotions or in the overall score.

The control and intervention group differ regarding the number of participants. Theoretically A and B subgroups were similar in sample size, however assistance to seminars is flexible due to academic organization. Therefore probably due to non controlled students schedule, control group's assistance was greater than assistance to intervention group. In further studies a higher number of students should be required in order to allow for losses.

We do not know the effect of longer, repetitive or individual online stimulations, which suggests new experiments to assess the efficacy of these different settings.

We also do not know the effect's duration. A subsequent test should therefore be conducted 1 to 6 months later to determine whether the effect of the training is maintained over time.

Although standard in clinical studies, the assessment with the Ekman test is too simple for the healthy population, which limits the range of improvement by placing a ceiling on many of the emotions. The use of lively tests (microexpressions) or with more ambiguous or gradual emotions could maximize the differences between the groups.

Given the reduced differences in recognition, perhaps it is worthwhile to assess the participants with poorer results and train these students specifically.

\section{Conflicts of Interest}

The authors declare no conflicts of interest regarding the publication of this paper.

\section{References}

Achinard, M. (2000). Doctor's and Patients' Facial Expressions and Suicide Reattempt Risk Assessment. Journal of Psychiatric Research, 34, 261-262. https://doi.org/10.1016/S0022-3956(00)00011-X

Becker, M. H., \& Maiman, L. A. (1975). Sociobehavioral Determinants of Compliance with Health and Medical Care Recommendations. Medical Care, 13, 10-24. https://doi.org/10.1097/00005650-197501000-00002

Eide, H., Quera, V., \& Finset, A. (2003). Exploring Rare Patient Behaviour with Sequential Analysis: An Illustration. Epidemiology and Psychiatric Sciences, 12, 109-114. https://doi.org/10.1017/S1121189X00006175

Ekman, P. (2004). Emotions Revealed: Recognising Facial Expression. British Medical Journal Careers, 75-76. http://archive.student.bmj.com/issues/04/04/education/140.php 
Endres, J., \& Laidlaw, A. (2009). Micro-Expression Recognition Training in Medical Students: A Pilot Study. BMC Medical Education, 9, 47. https://doi.org/10.1186/1472-6920-9-47

Haxby, J., Hoffman, E., \& Gobbini, M. (2002). Human Neural Systems for Face Recognition and Social Communication. Biological Psychiatry, 51, 59-67. https://doi.org/10.1016/S0006-3223(01)01330-0

Hojat, M., Louis, D. Z., Markham, F. W., Wender, R., Rabinowitz, C. et al. (2011). Physicians' Empathy and Clinical Outcomes for Diabetic Patients. Academic Medicine, 86, 359-364. https://doi.org/10.1097/ACM.0b013e3182086fe1

Kelley, J. M., Kraft-Todd, G., Schapira, L., Kossowsky, J., \& Riess, H. (2014). The Influence of the Patient-Clinician Relationship on Healthcare Outcomes: A Systematic Review and Meta-Analysis of Randomized Controlled Trials. PLOS ONE, 9, e94207. https://doi.org/10.1371/journal.pone.0094207

Kim, S. S., Kaplowitz, S., \& Johnston, M. V. (2004). The Effects of Physician Empathy on Patient Satisfaction and Compliance. Evaluation \& the Health Professions, 27, 237-251.

Kraft-Todd, G. T., Reinero, D. A., Kelley, J. M., Heberlein, A. S., Baer, L., \& Riess, H. (2017). Empathic Nonverbal Behavior Increases Ratings of Both Warmth and Competence in a Medical Context. PLoS ONE, 12, e0177758. https://doi.org/10.1371/journal.pone.0177758

Langewitz, W., Nübling, M., \& Weber, H. (2003) A Theory-Based Approach to Analysing Conversation Sequences. Epidemiology and Psychiatric Sciences, 12, 103-108. https://doi.org/10.1017/S1121189X00006163

Little, P., Everitt, H., Williamson, I., Warner, G., Moore, M. et al. (2001). Preferences of Patients Forpatient Centred Approach to Consultation in Primary Care: Observational Study. BMJ, 322, 468-472. https://doi.org/10.1136/bmj.322.7284.468

Lockwood, P. L. (2016). The Anatomy of Empathy: Vicarious Experience and Disorders of Social Cognition. Behavioural Brain Research, 311, 255-266. https://doi.org/10.1016/j.bbr.2016.05.048

Maroño Souto, Y., Vázquez Campo, M., Díaz Llenderrozas, F., Rodríguez Álvarez, M., Mateos, R., \& García Caballero, A. (2018). Randomized Clinical Trial with e-MotionalTraining 1.0 for Social Cognition Rehabilitation in Schizophrenia. Frontiers in Psychiatry, 9, 40. https://doi.org/10.3389/fpsyt.2018.00040

McCabe, R., Heath, C., Burns, T., \& Priebe, S. (2002). Engagement of Patients with Psychosis in the Consultation: Conversation Analytic Study. BMJ, 325, 1148-1151. https://doi.org/10.1136/bmj.325.7373.1148

Mead, N., \& Bower, P. (2000) Patient-Centredness: A Conceptual Framework and Review of the Empirical Literature. Social Science \& Medicine, 51, 1087-1110. https://doi.org/10.1016/S0277-9536(00)00098-8

Mentes, J., Teer, J., \& Cadogan, M. (2004). The Pain Experience of Cognitively Impaired Nursing Home Residents: Perceptions of Family Members and Certified Nursing Assistants. Pain Management Nursing, 5, 118-125. https://doi.org/10.1016/j.pmn.2004.01.001

Mercer, S. W., \& Reynolds, W. J. (2002). Empathy and Quality of Care. The British Journal of General Practice, 52, S9.

Norfolk, T., Birdi, K., \& Walsh, D. (2007). The Role of Empathy in Establishing Rapport Patient Centered Care on Outcomes. The Journal of Family Practice, 49, 796-804.

Riess, H., \& Kraft-Todd, G. (2014). E.M.P.A.T.H.Y.: A Tool to Enhance Nonverbal Communication between Clinicians and Their Patients. Academic Medicine, 89, 1108-1112. https://doi.org/10.1097/ACM.0000000000000287 
Rimondini, M., Del Piccolo, L., Goss, C., Mazzi, M. A., Paccaloni, M. et al. (2004). The Handling of Patient Cues and Expressed Emotions in Psychiatric Interviews after a Communication Skills Training. Patient Education and Counseling, 55, 311-312.

Squier, R. W. (1990) A Model of Empathic Understanding and Adherence to Treatment Regimens in Practitioner-Patient Relationships. Social Science \& Medicine, 30, 325-339. https://doi.org/10.1016/0277-9536(90)90188-X

Stewart, M., Brown, J. B., Donner, A., McWhinney, I. R., Oates, J. et al. (2000). The Impact of Consultation: A New Model. Medical Education, 41, 690-697.

Tamblyn, R., Abrhamowicz, M., Dauphinee, D., Wenghofer, E., Jacques, A., Klass, D., Smee, S., Blackmore, D., Winslade, N., Girard, N. et al. (2007). Physician Scores on a National Clinical Skills Examination as Predictors of Complaints to Medical Regulatory Authorities. The Journal of the American Medical Association, 298, 993-1001. https://doi.org/10.1001/jama.298.9.993

Van den Brink-Muinen, A., \& Caris-Verhallen, W. (2003). Doctors' Responses to Patients' Concerns: Testing the Use of Sequential Analysis. Epidemiology and Psychiatric Sciences, 12, 92-97. https://doi.org/10.1017/S1121189X0000614X

Van Dulmen, S., \& van den Brink-Muinen, A. (2004). Patients' Preferences and Experiences in Handling Emotions: A Study on Communication Sequences in Primary Care Medical Visits. Patient Education and Counseling, 55, 149-152.

Van Dulmen, S., Nübling, M., \& Langewitz, W. (2003). Doctor's Responses to Patients' Concerns; An Exploration of Communication Sequences in Gynaecology. Epidemiology and Psychiatric Sciences, 12, 98-102. https://doi.org/10.1017/S1121189X00006151

Vázquez-Campo, M., Maroño, Y., Lahera, G., Mateos, R., \& García-Caballero, A. (2016). e-Motional Training ${ }^{\otimes}$ : Pilot Study on a Novel Online Training Program on Social Cognition for Patients with Schizophrenia. Schizophrenia Research: Cognition, 4, 10-17. https://doi.org/10.1016/j.scog.2015.11.007

West, C. P., Huschka, M. M., Novotny, P. J., Sloan, J. A., Kolars, J. C., Habermann, T. M. et al. (2006). Association of Perceived Medical Errors with Resident Distress and Empathy: A Prospective Longitudinal Study. JAMA: The Journal of the American Medical Association, 296, 1071-1078. https://doi.org/10.1001/jama.296.9.1071

Young, A., Perrett, D., Calder, A., Sprengelmeyer, R., \& Ekman, P. (2002). Facial Expressions of Emotion-Stimuli and Tests (FEEST). Bury St Edmunds, Inglaterra: Thames Valley Test Company.

Zachariae, R., Pedersen, C. G., Jensen, A. B., Ehrnrooth, E., Rossen, P. B. et al. (2003). Association of Perceived Physician Communication Style with Patient Satisfaction, Distress, Cancer-Related Self-Efficacy, and Perceived Control over the Disease. British Journal of Cancer, 88, 658-665. https://doi.org/10.1038/sj.bjc.6600798

Zimmermann, C., Del Piccolo, L., \& Mazzi, M. A. (2003). Patient Cues and Medical Interviewing in General Practice: Examples of the Application of Sequential Analysis. Epidemiology and Psychiatric Sciences, 12, 115-123.

https://doi.org/10.1017/S1121189X00006187 